\title{
Importância da terapia por pressão negativa na prática clínica de enfermagem
}

\author{
The importance of therapy by negative pressure on nursing clinical practice \\ Importancia de la terapia con presión negativa en la práctica clínica de enfermería \\ Iris Medeiros Cavalcante ${ }^{1}$, Ednamare Pereira da Silva ${ }^{1 *}$.
}

\begin{abstract}
RESUMO
Objetivo: Descrever a importância da terapia por pressão negativa no tratamento de feridas, com ênfase em suas engrenagens de ação e as indicações terapêuticas. Métodos: Revisão integrativa da literatura, sendo apresentadas os seguintes estágios: iniciando pela escolha do tema e a seleção da argumentação e debate dos conhecimentos para a revisão da bibliografia eleita, exposição e esclarecimento dos dados a serem retirados dos documentos selecionados, evidenciando suas particularidades, tal como determinar seus valores analisando os seguintes descritores: terapêutica, tratamento de ferimentos com pressão negativa, ferimentos e lesões, cuidados de enfermagem. Resultados: Foi possível identificar que o uso da TPN acelera a cicatrização, reduz o tempo de tratamento e o risco de infecção, tem melhor custo-benefício conquistando mais profissionais devido as benesses proporcionadas. Considerações finais: Após revisão de variados estudos, infere-se que a Terapia por pressão negativa é uma importante aliada do enfermeiro no tratamento de feridas complexas, gerando resultados importantes para a saúde bem-estar do paciente.
\end{abstract}

Palavras-chave: Terapêutica, Pressão negativa, Ferimentos e lesões, Cuidados de enfermagem.

\begin{abstract}
Objective: Describe the importance of therapy by negative pressure on wound's treatment, focusing on the action gears and the therapeutics indications. Methods: Integrative literature review, with the following stages being presented: starting with the choice of the theme and the selection of the argumentation and debate of knowledge for the revision of the chosen bibliography, exposure, and clarification of the data to be taken from the selected documents, highlighting their particularities, such as determine their values by analyzing the following descriptors: therapy, negative pressure, wounds and injuries, nursing care. Results: It was possible to identify that the TPN usage accelerates cicatrization, minimizes the treatment's healing time and the risk of infection, and has best cost benefit alluring more professionals for its provided benefits. Final considerations: After reviewing various studies, it appears that negative pressure therapy is an important ally for the nurse on treating complex wounds, providing important results for the patient's health and well-being.
\end{abstract}

Key words: Therapy, Negative pressure, Wounds and injuries, Nursing care.

\section{RESUMEN}

Objetivo: Describir la importancia de la terapia de presión negativa en el tratamiento de heridas, con énfasis en sus engranajes de acción e indicaciones terapéuticas. Metodos: Revisión integradora de la literatura, presentándose las siguientes etapas: a partir de la elección del tema y la selección de la argumentación y debate de conocimientos para la revisión de la bibliografía elegida, exposición y aclaración de los datos a tomar de los documentos seleccionados, destacando sus particularidades, tales como determinar sus valores analizando los siguientes descriptores: terapia, tratamiento de heridas con presión negativa, heridas y traumatismos, cuidados de enfermería. Resultados: Se pudo identificar que el uso de TPN acelera la cicatrización, reduce el tiempo de tratamiento y el riesgo de infección, tiene una mejor relación costo-beneficio, ganando más profesionales por los beneficios brindados. Consideraciones finales: Luego de revisar varios estudios, parece que la terapia con presión negativa es un aliado importante para los enfermeros en el tratamiento de heridas complejas, generando resultados importantes para la salud y el bienestar del paciente.

Palabras clave: Terapéutica, Presión negativa, Heridas y traumatismos, Atención de enfermería.

${ }^{1}$ Centro Universitário Mauricio de Nassau (UNINASSAU), Lauro de Freitas - BA.

*E-mail: iris.cavalcante741@gmail.com 


\section{INTRODUÇÃO}

Uma ferida é representada por uma ruptura dos tecidos do corpo produzida por: traumas, processos degenerativos, inflamatórios, circulatórios, por defeito de formação ou por distúrbios e transformações sofridas em um organismo. É resultado de um processo patológico que se inicia no interior ou exterior do órgão ou parte do corpo onde ocorre o dano na estrutura ou atividade anatômica normal, podendo ser em maior ou menor grau (BERTOLINI JP, et al., 2018).

De acordo com a etiologia elas podem ser traumáticas, ou seja, provocadas acidentalmente por agentes cortantes, perfurantes, contundentes, por atrito, inoculações de veneno, mordeduras, queimadura; cirúrgicas, que são feridas agudas intencionais, preferencialmente realizadas em centro cirúrgico; patológicas, como as úlceras venosas, arteriais, diabéticas, neuropáticas, isquêmicas; e as iatrogênicas, causadas por resposta desfavorável ao tratamento médico ou cirúrgico, ou seja, induzida pelo próprio tratamento (EBERHARDT TD, et al., 2015). As lesões tidas como difíceis de tratar, são denominadas feridas complexas, o aumento da prevalência dessas feridas deve-se, fundamentalmente, ao envelhecimento da população e aos traumas que ocorrem nas grandes cidades (LIMA RVKS, et al., 2017).

O acréscimo dos gastos em tratamentos de feridas, como materiais, profissionais e internação são resultados do aparecimento de uma lesão complexa, bem como a elevação da morbimortalidade. Sendo de suma relevância que o enfermeiro, ao primeiro contato com o paciente, viabilize alternativas para acelerar o processo de cicatrização, reduzindo o tempo de hospitalização e consequentemente o retorno do paciente as suas atividades normais (SILVA JWL, et al., 2020).

A partir dessa necessidade de regresso às atividades em menor tempo é que se vem difundindo cada vez mais a utilização de Terapia por Pressão Negativa (TPN), também conhecida por Terapia por Pressão Subatmosférica, incorporada aos tratamentos de feridas em 1997, por Argenta e Morykwas, cuja ideia principal era a aceleração da reparação tecidual. Essa terapia é um tipo de terapêutica que possibilita a cicatrização em meio úmido, utilizando uma pressão subatmosférica, monitorada e localizada (LIMA RVKS, et al., 2017).

A pressão aplicada faz com que o exsudato presente seja sugado e absorvido por uma cobertura de espuma ou gaze, que recobre todo o leito da lesão, incluindo cavidades, tuneis e/ou galerias, que serão cobertos por uma película fina e transparente que veda toda a extensão da ferida, logo após é fixado um ducto de sucção, ligado a um reservatório que recolherá o material sugado, tudo isso monitorizado através de um computador, com parâmetros que possibilitam uma programação previa e com aviso sonoro de vazamentos (SILVA JWL, et al., 2020).

A utilização de TPN tem se expandido muito nos últimos anos, gerando inovações em sua empregabilidade, sendo, atualmente, indispensável no tratamento de feridas complexas, contribuindo para a investigação de áreas isquêmicas, melhorando a assimilação de enxertos de pele. $O$ tratamento de lesões agudas com esse sistema torna a troca de curativos menos frequente, em geral de 3 a 7 dias, levando ao tratamento completo da ferida, viabilizando os cuidados de enfermagem e reduzindo o risco de infecções (LIMA RVKS, et al., 2017).

Este estudo justifica-se em engendrar maior conhecimento sobre esse tipo de curativo no meio acadêmico, visto a escassez de investigação sobre o tema, sendo subutilizado não só pelo custo, mas pela insciência. Na prática clínica, o enfermeiro, especialista em feridas é o profissional mais capacitado para avaliar o leito da ferida e indicar o melhor curativo a ser aplicado, contudo com esse subaproveitamento devido ao custo, acaba não sendo adotado. A partir desse panorama, o objetivo desse estudo é descrever a importância da TPN no tratamento de feridas, com ênfase em suas ações e as indicações terapêuticas.

\section{MÉTODOS}

Essa pesquisa trata-se de revisão integrativa da literatura que se apoia no amparo de um estudo amplo, promovendo um debate sobre seus efeitos, bem como a análise para execução de novas investigações, justificando a compreensão de um evento, a partir de aprendizados anteriores (SOUSA LML, et al., 2017). 
Foram desenvolvidas as seguintes etapas: escolha do assunto e a triagem do debate do estudo para a revisão da literatura, elucidação dos dados a serem retirados das pesquisas eleitas, tal como sua especificação e mensuração de acordo com os seguintes descritores: terapêutica, tratamento de ferimentos com pressão negativa, ferimentos e lesões, cuidados de enfermagem.

Foram utilizadas como bases de dados para essa pesquisa o Google Acadêmico, Biblioteca Virtual em Saúde (BVS), Literatura Latino-Americana do Caribe em Ciências da Saúde (LILACS) e Revista Acervo Saúde, como critério de inclusão foram utilizados artigos indexados citados nessas fontes, com texto completo, idioma português, publicados entre 2015 e 2020, excluídos da pesquisa textos e artigos incompletos, em outras línguas e fora dos anos de seleção.

Figura 1 - Fluxo de seleção dos estudos para a revisão da literatura.

FLUXOGRAMA DE SELEÇÃ̈O DE ARTIGOS

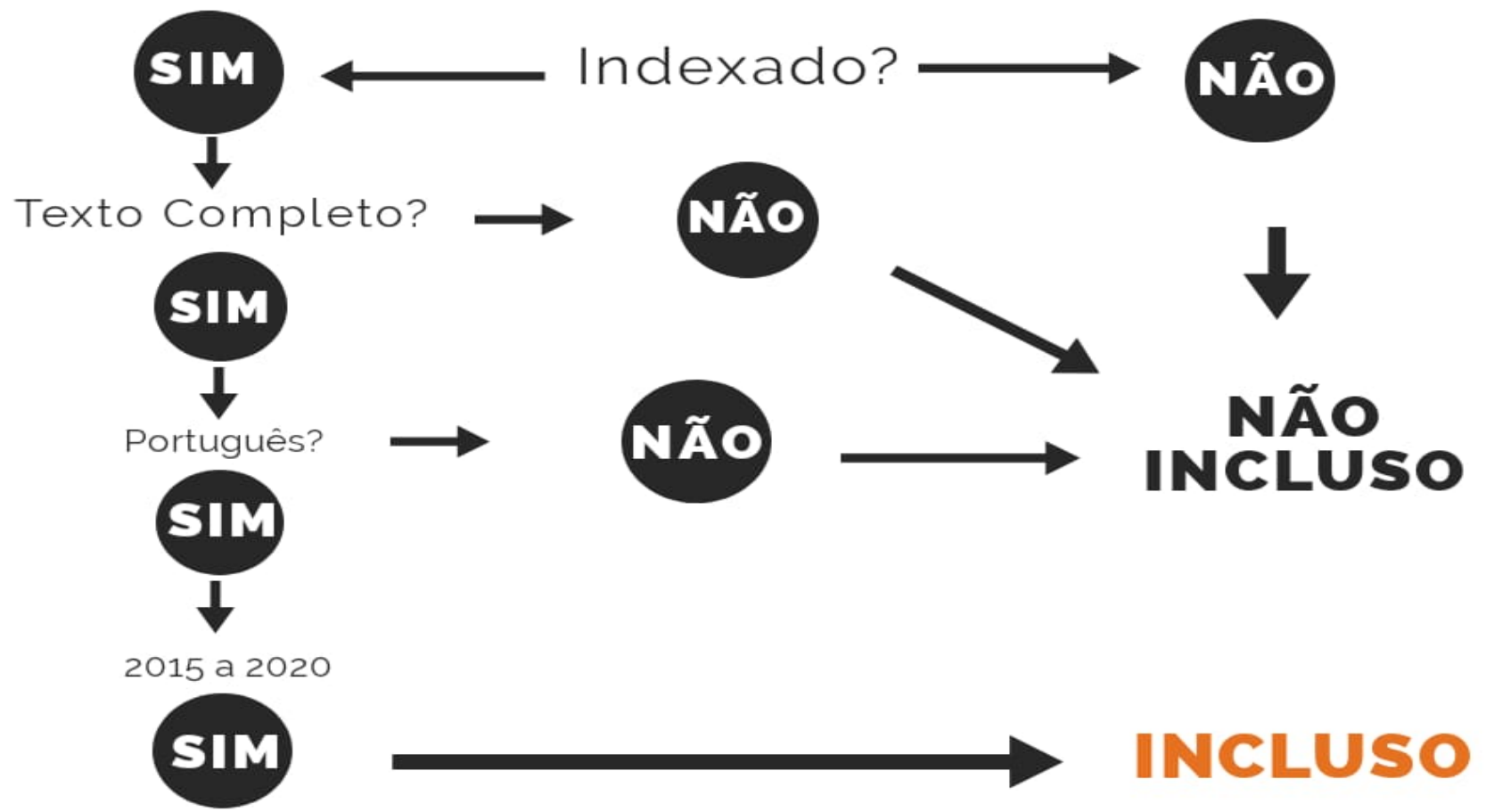

Fonte: Cavalcante IM e Silva EP, 2021.

\section{RESULTADOS}

Foram encontrados 70 artigos, após os critérios de inclusão e exclusão, foram selecionados 20 artigos. Segundo o ano de publicação, do total de 20 artigos 20\% foram publicados em 2015, 10\% em 2016, 30\% em 2017, 10\% em 2018, 15\% em 2019 e 15\% em 2020.

Classificando por região, foi possível perceber que a região sul e sudeste são as que mais difundem pesquisas sobre a TPN, ficando empatadas com 35\% dos artigos referenciados cada região, seguido da região nordeste com 15\%, região centro-oeste com 5\%. Também foram encontrados $10 \%$ de publicações em português de Portugal. Sobre o tipo de estudo foram encontrados revisão integrativa com $40 \%$ dos artigos, relatos de casos $20 \%$ dos artigos, estudos qualitativos $15 \%$, estudo observacional $5 \%$, estudo clínico prospectivo $10 \%$, estudo comparativo $5 \%$ e revisão retrospectiva de prontuários $5 \%$

A partir da análise dos artigos selecionados, foram elaboradas as seguintes categorias, "a importância da Terapia por pressão negativa" e "a terapia por pressão negativa e suas implicações". 
Quadro 1 - Distribuição das publicações incluídas segundo os autores, ano, objetivo principal, região, tipo de estudo e principais resultados.

\begin{tabular}{|c|c|c|c|c|c|c|}
\hline № & Autor & Ano & Objetivo & Região & $\begin{array}{l}\text { Tipo de } \\
\text { estudo }\end{array}$ & Principais resultados \\
\hline 1 & $\begin{array}{l}\text { ABREU RLD, } \\
\text { et al. }\end{array}$ & 2016 & $\begin{array}{c}\text { Evidenciar a aplicação do uso da pressão } \\
\text { negativa subatmosférica no tratamento de } \\
\text { feridas e a assistência de enfermagem a } \\
\text { terapia por VAC. }\end{array}$ & Sudeste & $\begin{array}{l}\text { Estudo } \\
\text { qualitativo }\end{array}$ & $\begin{array}{l}\text { Dentre as vantagens associadas ao uso da pressão negativa: } \\
\text { a diminuição do edema através da força de sucção e } \\
\text { consequente absorção exercida pelo vácuo sobre a ferida, a } \\
\text { redução do edema e restauro do fluxo vascular e linfático; do } \\
\text { mesmo modo a sucção atua na aspiração do exsudato e } \\
\text { remoção das metaloproteinases e citosinas pró-inflamatórias, } \\
\text { responsáveis pela apoptose e degradação da matriz } \\
\text { extracelular. }\end{array}$ \\
\hline 2 & $\begin{array}{c}\text { AZEVEDO } \\
\text { AP,et al. }\end{array}$ & 2020 & $\begin{array}{l}\text { Estudo da comparação de custos } \\
\text { efetividade e tempo de tratamento de } \\
\text { lesão por pressão em dois pacientes com } \\
\text { o mesmo perfil clínico-patológico } \\
\text { utilizando-se insumos e técnicas } \\
\text { diferentes em cada um deles. }\end{array}$ & Sul & $\begin{array}{c}\text { Estudo } \\
\text { prospectivo }\end{array}$ & $\begin{array}{l}\text { Após } 30 \text { dias de tratamento das lesões, as duas pacientes (A } \\
\text { e B) que tinham o mesmo perfil clínico e patológico, fecharam } \\
\text { as lesões em períodos praticamente idênticos. Na comparação } \\
\text { de valores, o custo com o tratamento da lesão do paciente B } \\
\text { foi } 36,6 \% \text { menor que o custo do paciente } A \text {. }\end{array}$ \\
\hline 3 & $\begin{array}{l}\text { BENTO } \\
\text { SS.et al. }\end{array}$ & 2015 & $\begin{array}{l}\text { Observar a associação do hidrogel e filme } \\
\text { transparente no tratamento ferida crônica } \\
\text { com necrose seca e úmida. }\end{array}$ & Sudeste & $\begin{array}{l}\text { Relato de } \\
\text { caso }\end{array}$ & $\begin{array}{l}\text { A cicatrização completa da lesão em braço esquerdo ocorreu } \\
\text { em } 41 \text { dias. Concluímos que a associação do hidrogel e filme } \\
\text { de PVC como terapia tópica para o tratamento de ferida } \\
\text { necrosada em braço, apresentou resultado satisfatório e } \\
\text { significativa rapidez na cicatrização, além do baixo custo que } \\
\text { viabilizou o tratamento da ferida devido sua grande extensão. }\end{array}$ \\
\hline 4 & $\begin{array}{l}\text { BERTOLINI } \\
\text { JP, et al. }\end{array}$ & 2018 & $\begin{array}{l}\text { A instrumentalização das ações } \\
\text { profissionais e a sistematização da } \\
\text { assistência prestada de forma a } \\
\text { organizar, oferecer subsídios e possibilitar } \\
\text { escolhas apropriadas e disponíveis para o } \\
\text { enfrentamento de problemas relativos ao } \\
\text { tratamento de feridas }\end{array}$ & Sul & $\begin{array}{c}\text { Estudo } \\
\text { Qualitativo }\end{array}$ & $\begin{array}{l}\text { O Enfermeiro precisa estar plenamente consciente quanto aos } \\
\text { atos praticados ou a serem assumidos, respeitando seus } \\
\text { limites de competência e responsabilidade. Sendo necessária } \\
\text { a busca pelo aprimoramento e desenvolvimento de } \\
\text { competências, por meio da realização de cursos de } \\
\text { capacitação, e, especialização resguardando a segurança do } \\
\text { paciente e o exercício legal da profissão. }\end{array}$ \\
\hline 5 & $\begin{array}{l}\text { CALDAS NG, } \\
\text { et al. }\end{array}$ & 2019 & $\begin{array}{l}\text { Relato de casos e evidencia de como o } \\
\text { uso da terapia a vácuo tem ganhado } \\
\text { espaço no tratamento de feridas } \\
\text { complexas, sendo efetivo no manejo das } \\
\text { lesões provocadas pela Síndrome de } \\
\text { Fournier. }\end{array}$ & Sudeste & $\begin{array}{l}\text { Relato de } \\
\text { caso }\end{array}$ & $\begin{array}{l}\text { O uso de terapia a vácuo possibilita o fechamento primário da } \\
\text { ferida em menor tempo, visto que acelera a cicatrização, } \\
\text { aproxima suas bordas e possibilita tratamento em } \\
\text { procedimento único. Nos casos conduzidos, após a terapia a } \\
\text { vácuo, os pacientes foram submetidos a fechamento da ferida, } \\
\text { com boa evolução pós-operatória e resultado estético } \\
\text { satisfatório. }\end{array}$ \\
\hline
\end{tabular}




\begin{tabular}{|c|c|c|c|c|c|c|}
\hline № & Autor & Ano & Objetivo & Região & $\begin{array}{l}\text { Tipo de } \\
\text { estudo }\end{array}$ & Principais resultados \\
\hline 6 & $\begin{array}{l}\text { EBERHARD } \\
\text { T TD, et al. }\end{array}$ & 2015 & $\begin{array}{c}\text { Identificar a produção científica acerca da } \\
\text { mensuração de feridas. }\end{array}$ & Sul & $\begin{array}{l}\text { Revisão } \\
\text { sistemática de } \\
\text { literatura }\end{array}$ & $\begin{array}{l}\text { Nove estudos foram incluídos nesta revisão, cinco relatavam } \\
\text { sobre técnicas não invasivas, dois estudos abordaram } \\
\text { técnicas invasivas e dois estudos relatavam sobre técnicas } \\
\text { invasivas versus não invasivas para mensuração de feridas. }\end{array}$ \\
\hline 7 & $\begin{array}{l}\text { GALLAFRIO } \\
\text { ST, et al }\end{array}$ & 2017 & $\begin{array}{l}\text { Realizar levantamento dos pacientes } \\
\text { vítimas complicação que tenham sido } \\
\text { tratados segundo protocolo desenvolvido } \\
\text { e aprimorado no InCor - HCFMUSP, e } \\
\text { que tenham sido operados por um } \\
\text { mesmo cirurgião plástico, a fim de } \\
\text { analisar o perfil epidemiológico, e } \\
\text { eventual indicador de pior prognóstico } \\
\text { dentre os exames colhidos habitualmente } \\
\text { desses pacientes. }\end{array}$ & Sudeste & $\begin{array}{c}\text { Revisão } \\
\text { retrospectiva } \\
\text { de prontuários }\end{array}$ & $\begin{array}{l}\text { Os dados analisados nos permitem concluir que o método } \\
\text { padronizado adotado trouxe impacto na redução da } \\
\text { mortalidade global dos pacientes, além da redução de recidiva } \\
\text { e reinternações. Identificamos, ainda, indicadores de pior } \\
\text { prognóstico como PCR e leucograma no momento do } \\
\text { diagnóstico e indicação da aplicação do protocolo. }\end{array}$ \\
\hline 8 & $\begin{array}{l}\text { GARGUR } \\
\text { SM, SILVA } \\
\text { GN. }\end{array}$ & 2018 & $\begin{array}{l}\text { Padronizar as ações relacionadas ao } \\
\text { atendimento dos pacientes com feridas, } \\
\text { unificando as condutas realizadas pela } \\
\text { equipe de enfermagem, sistematizando a } \\
\text { assistência no âmbito do atendimento ao } \\
\text { usuário com lesões crônicas. }\end{array}$ & Nordeste & $\begin{array}{l}\text { Estudo } \\
\text { Qualitativo }\end{array}$ & $\begin{array}{l}\text { Instrumentalizar as ações dos profissionais no manejo de } \\
\text { feridas, permitindo um atendimento integrado, além de } \\
\text { qualificar as ações de prevenção, minimizar fatores que } \\
\text { retardam a cicatrização e prolongam o tratamento, } \\
\text { favorecendo a alta precoce e o retorno do paciente a } \\
\text { sociedade. }\end{array}$ \\
\hline 9 & $\begin{array}{l}\text { KAMAMOTO } \\
\mathrm{F} .\end{array}$ & 2016 & $\begin{array}{l}\text { Este estudo comparou a terapia de baixo } \\
\text { custo (grupo USP) com a terapia padrão } \\
\text { no Mercado (VAC system®, KCI, San } \\
\text { Antônio - Texas) - Grupo VAC em um } \\
\text { desenho prospectivo, randomizado, no } \\
\text { formato de não inferioridade. }\end{array}$ & Sudeste & $\begin{array}{l}\text { Estudo } \\
\text { comparativo }\end{array}$ & $\begin{array}{l}\text { Em relação ao tempo necessário para ferida estar apta para a } \\
\text { cirurgia de retalho, o Grupo USP apresentou um resultado de } \\
\qquad 9,6 \pm 4,5 \text { dias. }\end{array}$ \\
\hline 10 & $\begin{array}{l}\text { LEITÃO F, et } \\
\quad \text { al. }\end{array}$ & 2015 & $\begin{array}{c}\text { Perceber se a TPN é uma alternativa } \\
\text { eficaz ao tratamento convencional para o } \\
\text { tratamento de feridas em doentes } \\
\text { diabéticos com feridas nos membros } \\
\text { inferiores. }\end{array}$ & Portugal & $\begin{array}{l}\text { Revisão } \\
\text { sistemática da } \\
\text { literatura }\end{array}$ & $\begin{array}{l}\text { Em termos de resultados clínicos não existem diferenças } \\
\text { significativas na redução do tamanho da ferida ou no tempo de } \\
\text { cicatrização, sendo ambas capazes de proporcionar efeitos } \\
\text { clínicos relevantes, devendo por isso ser escolhidas consoante } \\
\text { a facilidade de aplicação, experiência de quem aplica, } \\
\text { disponibilidade e custo. }\end{array}$ \\
\hline
\end{tabular}




\begin{tabular}{|c|c|c|c|c|c|c|}
\hline № & Autor & Ano & Objetivo & Região & $\begin{array}{l}\text { Tipo de } \\
\text { estudo }\end{array}$ & Principais resultados \\
\hline 11 & $\begin{array}{l}\text { LIMA RVKS, } \\
\quad \text { et al. }\end{array}$ & 2017 & $\begin{array}{l}\text { O objetivo desse estudo é avaliar a } \\
\text { eficácia da terapia por pressão negativa } \\
\text { (TPN) no tratamento de feridas } \\
\text { complexas, com ênfase em seus } \\
\text { mecanismos de ação e principais } \\
\text { indicações terapêuticas. }\end{array}$ & Sudeste & $\begin{array}{l}\text { Revisão } \\
\text { sistemática da } \\
\text { literatura }\end{array}$ & $\begin{array}{c}\text { O conhecimento adequado do seu mecanismo de ação e das } \\
\text { suas principais indicações pode otimizar e racionalizar seu } \\
\text { uso, levando a resultados mais efetivos na resolução das } \\
\text { feridas. A TPN deve compor o arsenal terapêutico dos } \\
\text { cirurgiões para o tratamento das mais variadas feridas } \\
\text { complexas. }\end{array}$ \\
\hline 12 & $\begin{array}{l}\text { MILCHESKI } \\
\text { DA, et al }\end{array}$ & 2017 & $\begin{array}{l}\text { relatar a experiência inicial com a terapia } \\
\text { por pressão negativa por instilação em } \\
\text { feridas complexas infectadas ou } \\
\text { contaminadas. }\end{array}$ & Sudeste & $\begin{array}{c}\text { Estudo clínico } \\
\text { prospectivo }\end{array}$ & $\begin{array}{c}\text { Foram operados } 10 \text { pacientes com feridas complexas } \\
\text { contaminadas ou infectadas. O no médio de trocas da TPNi foi } \\
1,4, \text { o } n^{\circ} \text { médio total de cirurgias foi de } 2,4 \text {, o intervalo até a } \\
\text { cobertura da ferida foi de } 6,3 \text { dias e o intervalo até a alta foi de } \\
11,4 \text { dias. }\end{array}$ \\
\hline 13 & $\begin{array}{l}\text { OLIVEIRA } \\
\text { JFS,et al. }\end{array}$ & 2017 & $\begin{array}{c}\text { Identificar a evolução do processo de } \\
\text { cicatrização das feridas crônicas, através } \\
\text { do uso da terapia por pressão negativa e } \\
\text { informar os benefícios, como avanço da } \\
\text { tecnologia. }\end{array}$ & Nordeste & $\begin{array}{l}\text { Revisão } \\
\text { sistemática da } \\
\text { literatura }\end{array}$ & $\begin{array}{c}\text { Obter uma cicatrização mais rápida leva o cliente a uma } \\
\text { permanência menor de hospitalização e retorno mais rápido a } \\
\text { vida social. }\end{array}$ \\
\hline 14 & $\begin{array}{l}\text { OLIVEIRA } \\
\mathrm{MC} \text {, et al }\end{array}$ & 2019 & $\begin{array}{l}\text { Descrever as relações entre as } \\
\text { características epidemiológicas e clínicas } \\
\text { de pacientes no pós-operatório de cirurgia } \\
\text { cardíaca submetidos a terapia por } \\
\text { pressão negativa para o tratamento de } \\
\text { infecção do sítio cirúrgico. }\end{array}$ & $\begin{array}{l}\text { Centro- } \\
\text { oeste }\end{array}$ & $\begin{array}{l}\text { Estudo } \\
\text { observacional, } \\
\text { do tipo } \\
\text { transversal } \\
\text { analítico }\end{array}$ & $\begin{array}{c}\text { Foram incluídos prontuários de } 117 \text { pacientes, submetidos } \\
\text { principalmente a cirurgia de revascularização do miocárdio e } \\
\text { com infecção do sítio cirúrgico incisional profunda (88; } 75.2 \%) \text {. } \\
\text { A terapia por pressão negativa foi utilizada em média por } 16 \\
( \pm 9.5) \text { dias/paciente; } 1.7 \% \text { tiveram complicações associadas a } \\
\text { terapia e } 53.8 \% \text { apresentaram desconforto, principalmente dor } \\
(93.6 \%) .\end{array}$ \\
\hline 15 & $\begin{array}{l}\text { PEREIRA } \\
\text { TO, et al. }\end{array}$ & 2020 & $\begin{array}{l}\text { Descrever o uso da terapia por pressão } \\
\text { subatmosférica em lesão por pressão. }\end{array}$ & Sul & $\begin{array}{l}\text { Relato } \\
\text { de caso }\end{array}$ & $\begin{array}{l}\text { Percebeu-se que a Lesão por Pressão em estágio III melhorou } \\
\text { consideravelmente o seu aspecto após o uso da terapia por } \\
\text { pressão negativa caseira, o dispositivo mostrou-se eficaz } \\
\text { ajudando na redução da lesão, erradicação de dor e exsudato, } \\
\text { estimulando a neovascularização e a diminuição da carga } \\
\text { microbiótica local. }\end{array}$ \\
\hline
\end{tabular}




\begin{tabular}{|c|c|c|c|c|c|c|}
\hline № & Autor & Ano & Objetivo & Região & $\begin{array}{l}\text { Tipo de } \\
\text { estudo }\end{array}$ & Principais resultados \\
\hline 16 & PASSONI R & 2015 & $\begin{array}{c}\text { Descrever a experiência com o uso da } \\
\text { terapia por pressão negativa artesanal } \\
\text { como adjuvante na autoenxertia cutânea } \\
\text { em trauma ortopédico, fundamentado na } \\
\text { vivência prática ao manejo clínico de } \\
\text { ferida complexa em paciente acometido } \\
\text { por trauma ortopédico. }\end{array}$ & Sul & $\begin{array}{l}\text { Relato } \\
\text { de caso }\end{array}$ & $\begin{array}{c}\text { A utilização da terapia subatmosférica de maneira artesanal } \\
\text { apresentou resultados positivos significativos, semelhante } \\
\text { àqueles obtidos com a utilização de produtos industrializados, } \\
\text { pois possibilitou o reparo tecidual do ferimento complexo e } \\
\text { viabilizou a autoenxertia com sucesso. }\end{array}$ \\
\hline 17 & $\begin{array}{l}\text { SANTOS TL, } \\
\quad \text { et al. }\end{array}$ & 2019 & $\begin{array}{l}\text { Buscar na literatura cientifica evidências } \\
\text { sobre uso da terapia por pressão negativa } \\
\text { no tratamento de feridas. }\end{array}$ & Nordeste & $\begin{array}{l}\text { Revisão } \\
\text { integrativa da } \\
\text { literatura }\end{array}$ & $\begin{array}{c}\text { Terapia por pressão negativa é um método terapêutico eficaz } \\
\text { no tratamento das feridas crônicas e agudas, complexas e } \\
\text { infectadas. O método permitindo maior controle sobre o } \\
\text { ambiente da ferida reduzindo o edema, removendo exsudato e } \\
\text { material infeccioso, além de possibilitar a utilização de } \\
\text { soluções tópicas diretamente nos tecidos afetados, criando } \\
\text { assim um ambiente favorável para a cicatrização de feridas } \\
\text { por dá estimulação da formação de tecido de granulação e } \\
\text { perfusão. }\end{array}$ \\
\hline 18 & $\begin{array}{l}\text { SILVA ACO, } \\
\quad \text { et al. }\end{array}$ & 2017 & $\begin{array}{c}\text { Conhecer as principais coberturas usadas } \\
\text { no tratamento de feridas }\end{array}$ & Sul & $\begin{array}{l}\text { Revisão } \\
\text { integrativa da } \\
\text { literatura }\end{array}$ & $\begin{array}{c}\text { Através do presente estudo, obteve-se a oportunidade de } \\
\text { conhecer as coberturas utilizadas em feridas de diferentes } \\
\text { origens e grau, seu mecanismo de ação e o intervalo da troca } \\
\text { de curativo. }\end{array}$ \\
\hline 19 & $\begin{array}{l}\text { SILVA JWL, } \\
\quad \text { et al. }\end{array}$ & 2020 & $\begin{array}{l}\text { Demonstrar o manejo e os benefícios do } \\
\text { tratamento de lesões complexas por TPN. }\end{array}$ & Sul & $\begin{array}{l}\text { Revisão } \\
\text { integrativa da } \\
\text { literatura }\end{array}$ & $\begin{array}{l}\text { A TPN apresenta melhor eficácia e maiores benefícios para o } \\
\text { paciente, tais como redução do exsudato, edema, dor e } \\
\text { infecções; rápida cicatrização: angiogênese mais satisfatória e } \\
\text { presença de um leito propício para cicatrização. }\end{array}$ \\
\hline 20 & $\begin{array}{l}\text { SOUSA LML, } \\
\quad \text { et al. }\end{array}$ & 2017 & $\begin{array}{l}\text { Apresentar os conceitos gerais e as } \\
\text { etapas para a elaboração de uma revisão } \\
\text { integrativa da literatura, com base na } \\
\text { mais recente evidência científica. }\end{array}$ & Portugal & $\begin{array}{l}\text { Revisão } \\
\text { integrativa da } \\
\text { literatura }\end{array}$ & $\begin{array}{l}\text { Apresenta-se as seis fases do processo de elaboração da } \\
\text { revisão integrativa: identificação do tema e elaboração da } \\
\text { questão de pesquisa, amostragem ou pesquisa da literatura, } \\
\text { colheita de dados, análise crítica dos estudos incluídos, } \\
\text { interpretação e discussão dos resultados e apresentação da } \\
\text { revisão/síntese do conhecimento. }\end{array}$ \\
\hline
\end{tabular}

Fonte: Cavalcante IM e Silva EP, 2021. 


\section{DISCUSSÃO}

\section{Importância da Terapia por Pressão Negativa}

Após a leitura dos artigos selecionados, foi possível identificar que o uso da terapia por pressão negativa no tratamento de feridas complexas, tem obtido cada vez mais adeptos devido às suas inúmeras vantagens, tais como acelera o processo de cicatrização, redução no tempo de tratamento, redução do risco de infecção e melhor custo-efetivo.

Santos TL, et al. (2019), observaram que a TPN possui preço alto, porem quando se reflete sobre todos os benefícios quando comparados aos curativos convencionais, verifica-se uma ótima relação de custovantagem com a escolha do curativo a vácuo. Exatamente porque proporciona o fechamento completo da ferida ou concede a preparação do leito em tempo reduzido para o fechamento posterior, utilizando transplantes de pele ou processos cirúrgicos de fechamento de deiscência.

Para Kamamoto $F$ (2016), em relação à cicatrização da ferida, a satisfação nos resultados advém de uma regeneração mais rápida, com menores riscos de contaminação e fechamento completo da lesão em menor tempo do que se utilizasse um outro tipo de curativo. A modalidade de terapia por pressão negativa propõese a redução no tempo de tratamento e risco de infecção gerando melhor custo-efetividade em comparação a outros curativos, tipo o alginato de cálcio, com a utilização de maior quantidade de material, porem menor tempo gasto de cuidados de enfermagem.

Lima RVKS, et al. (2017), asseguram que apesar das despesas dos insumos, esses valores são abrandados com a diminuição das contas hospitalares, exatamente por minimizar a estada do paciente em uma unidade de saúde. Os médicos e enfermeiros envolvidos nos cuidados de feridas complexas, tem despendido cada vez mais atenção para seu tratamento, buscando a utilização de tecnologias mais modernas e se preocupando com os impactos nos custos institucionais que esses tratamentos acarretam.

Nota-se que os três autores concordam com a informação de que o uso de TPN gera um tempo menor de hospitalização, sendo esta informação discutível, entrando em discordância com uma minoria dos autores que lidam com TPN ou com pressão subatmosférica, contudo todos pactuam que tem uma menor taxa de morbi-mortalidade, sendo um mecanismo importante para o manejo de feridas, além de mais cômodo para o paciente e com valor análogo aos curativos convencionais, com resultados melhores e indicação prévia para reconstrução cirúrgica.

A ação de cicatrização organiza-se em quatro fases: a hemostática, inflamatória, proliferativa e a reparadora, cada uma com suas especificidades e existência estabelecida, contudo as feridas complexas não acompanham essas etapas, seja por prejuízo tecidual, infecção, por doenças coadjuvantes que afetam a cicatrização ou danos em tecidos externos, promovendo uma manutenção complicada da terapia, gerando a necessidade de mediação de outras áreas da medicina, para uma cicatrização completa (PEREIRA TO, et al., 2020). Silva ACO, et al. (2017), corroboram os conceitos de cicatrização e feridas complexas com Pereira TO, et al. (2020), argumentando que: após ocorrida a ruptura no tecido, o organismo inicia o processo de cicatrização, que será dividida em quatro fases que se seguem: hemostasia, inflamatória, fase proliferativa e reparadora gerando novos tecidos epiteliais. As feridas com essas características, são chamadas feridas agudas.

A feridas complexas não seguem essas mesmas particularidades, muitas vezes por terem alguma infecção associada, por haver perda significativa de matéria, ou por algum tipo de doença sistêmica dificultando o fechamento (GARGUR SM e SILVA GN, 2018). Os autores consideram a expressão ferida complexa relativamente nova, utilizada para designar feridas que desafiam a equipe de enfermagem e a equipe multidisciplinar, pois tem uma difícil cicatrização, por esse motivo é que a TPN é a mais indicada para seu tratamento, já que tem como objetivo acelerar o processo cicatricial, tornando-se a mais indicada para tal processo.

A utilização do curativo correto para determinados tipos de feridas, com a avaliação dos benefícios e dos custos gerados serão aspectos a serem considerados no momento da escolha do tipo de curativo, que devem ser adequados à natureza, à localização e ao tamanho da ferida. Embora haja uma grande variedade de 
curativos, um só tipo de curativo não preenche os requisitos para ser aplicado em todos os tipos de feridas cutâneas (BENTO SS, et al., 2015).

Por não haver um protocolo específico para cada tipo de feridas, o enfermeiro deverá avaliar o leito, se tem exsudato, necrose e tecido regenerativo, para a partir daí escolher o melhor tipo de curativo. Mesmo assim, não significa que esta será a escolha definitiva até o fechamento completo da lesão. Ressalta-se ainda que o tratamento de feridas deverá aliar além das habilidades e da expertise o conhecimento científico (PASSONI R, et al., 2015). Bento SS, et al. (2015) e Passione R, et al. (2015) adotam a mesma visão sobre a escolha para o tipo de cobertura, que será sempre discricionário, isto é, o profissional responsável tem livre escolha sobre as opções disponíveis. Diante dessas informações é que a enfermagem chega na frente, se destacando por serem referência, no que concerne à avaliação e conduta em face aos mais diversos curativos e coberturas.

Justamente por isso, Gallafrio ST, et al. (2017), cita em seu artigo que o Instituto do Coração do Hospital das Clínicas da Universidade de São Paulo (InCor HC-FMUSP), entre suas opções de escolha optou pelo protocolo de TPN, para lhe dar com o tratamento da ferida cirúrgica cardíaca complicada após estenostomia realizando o desbridamento agressivo da ferida logo na primeira abordagem e instalação da terapia por pressão negativa. Após a revitalização da ferida, busca-se fazer a oclusão com retalhos fasciocutâneos ou miocutâneos, a fim de melhorar a vascularização do esterno afetada e com isso melhorar a infecção.

O uso dos curativos a vácuo, sua composição, seu mecanismo de ação, as indicações e contraindicações, forma de utilização, periodicidade das trocas, vantagens e desvantagens do seu emprego na prática clínica devem estar associados a uma avaliação do leito da ferida e o desenvolvimento cicatricial desta (AZEVEDO AP, et al., 2020). O autor não chega a ser unanime em relação à escolha, tão pouco a uma preferência ou indicação, tudo vai depender da avaliação do tipo, do grau de classificação e da profundidade do ferimento em questão e dos tipos de coberturas e curativos disponíveis na unidade de saúde ou quanto o paciente pode investir neles. De acordo com Eberhardt TD, et al. (2015), o método de aferição com o propósito de comparação é de suma importância para avaliação da lesão, devendo ser periódicas, para que os dados encontrados possam ser confrontados e verificada a velocidade da cicatrização, estabelecendo com isso o tipo de cobertura que deverá ser empregada, ou caso não esteja sendo eficaz, refletir sobre um novo tipo de curativo que se fará uso.

Tanto Azevedo AP, et al. (2020), quanto Eberhardt DT, et al. (2015), concordam que a indicação de qualquer curativo depende de uma avaliação previa da lesão, para a partir daí escolher o mecanismo de fechamento. Até porque não se pode afirmar que determinado curativo está sendo ou não eficaz, sem antes ser estabelecido um parâmetro inicial de dimensões e aspectos. Eberhardt DT, et al. (2015), também acolhem a ideia de que a escolha do método terapêutico deve albergar as circunstâncias clínicas, psicossociais e econômicas do paciente, os sistemas ou órgão danificado, suas condições nutricionais ou comorbidades que possam interferir no desempenho da recuperação. Exatamente porque, sendo prescrito um curativo que o plano não tenha cobertura ou não seja bancado pelo Sistema Único de Saúde, o paciente terá que arcar com os custos, podendo gerar frustrações, baixa autoestima e pouca adesão a outros tratamentos.

Portanto, percebe-se que a importância da TPN está vinculada à uma regeneração mais rápida, à diminuição do tempo de hospitalização, à redução do risco de infecção e consequentemente o de morbimortalidade. Infelizmente ainda é considerado um tratamento caro, deixando muitas vezes de ser utilizado pelo Sistema Único de Saúde e pelos planos de saúde, sendo dada preferência a curativos de custos mais baixos, porém com tempo maior de uso.

\section{A Terapia por Pressão Negativa e suas implicações}

A Terapia por Pressão Negativa é um equipamento com a finalidade de, a partir da aplicação de pressão negativa sob as margens da ferida, gerar tecido de granulação, fibroblastos e o surgimento de novas células, gerando uma aceleração no processo de cicatrização (ABREU RLD, et al., 2016).

Para instalação do curativo, será feito o desbridamento da ferida, colocando uma esponja somente no leito de ferida, preservando a pele sã, e com um filme plástico adesivo será feita a vedação. A partir daí é conectado 
à máquina ou a um mecanismo de vácuo de parede hospitalar, a pressão habitualmente utilizada é $125 \mathrm{mmHg}$, no entanto pode variar entre $-50 \mathrm{mmHg}$ a $-150 \mathrm{mmHg}$, sempre mantido sob controle (LEITÃO F, et al., 2015). Esses valores são divergentes entre autores, o que foi percebido é que valores inferiores à $50 \mathrm{mmHg}$ são insuficientes, não obtendo resultados satisfatórios, quando superiores a $-150 \mathrm{mmHg}$ podem ser danosos aos tecidos, gerando dor aos pacientes.

A pressão pode variar quanto ao modo de aplicação, podendo ser contínua, se mantendo constante todo o tempo, intermitente, oscilando períodos de pressão negativa e sem pressão, e a intermitente que atua com mudanças repentinas no valor da pressão aplicada. Atualmente, a intermitente, é a menos utilizada, pois essa mudança súbita acaba causando sofrimento aos pacientes (AZEVEDO AP, et al., 2020).

Quanto a pressão que será utilizada, percebe-se na discussão entre Leitão F, et al. (2015) e Azevedo AP (2020) não existir um consenso, o que há são valores mínimo e máximo, que também será facultado ao profissional a escolha. Também não foi observado em nenhum outro artigo, valores específicos para utilização de pressão subatmosférica, sendo avaliado os níveis consumidos de acordo com a evolução do paciente. $O$ que pode inibir a evolução correta da cicatrização. Dessa forma, observa-se que esse tipo de recurso pode ser importante no tratamento de diversos tipos de ferimentos, causados por doenças crônicas, como por exemplo: feridas crônicas, agudas, traumáticas, deiscências, úlceras por pressão, úlceras diabéticas, retalhos e enxertos e queimaduras de densidade parcial, tendo resultados melhores que outros tipos de coberturas tradicionalmente utilizadas (LEITÃO F, et al., 2015).

Como indicação para o uso de curativos a vácuo, consideram que devem ser para tratar pacientes diabéticos, gangrena necrótica, feridas crônicas, infectadas, cirúrgicas, vasculares e síndrome abdominal compartimental, a Terapia de Pressão Negativa (TPN) é uma grande aliada no tratamento de feridas complexas (LIMA RVKS, et al., 2017). Independente da forma de escolha e indicação da terapia em questão, todo esse processo é significativo para que o desenvolvimento cicatricial seja efetivo, determinando a oclusão completa do ferimento. Ainda assim existem alguns casos em que não está indicada a TPN.

Segundo Caldas NG, et al. (2019), os curativos a vácuo servem para estimular a angiogênese e elevar a produção de tecidos novos, desbridamento do tecido necrótico, redução do espaço desvitalizado, de líquidos e secreção purulenta, que dificultam o fechamento da ferida. Os referidos autores não conjecturam o uso para se tratar doenças especificas, mas sim avaliar o sítio da ferida para que seja determinado um curativo, seja este TPN ou outros.

Leitão F, et al. (2015), consideram que terapia por pressão negativa está contraindicada para feridas de etiologia arterial severa e cavidades que não podem ser exploradas. E que se deve ter cautela em pacientes hipocoagulantes, com hemorragia ativa ou problemas hemostáticos, desnutridos ou doentes que não colaboram com a terapia. Devem ser contraindicadas nesses casos pelo risco de ampliar ou iniciar uma hemorragia, o que geraria um risco para a vida do paciente.

Oliveira JFS, et al. (2017), complementam ainda que ferimentos com necrose, com exposição de órgãos, nervos ou estruturas vasculares não deve ser indicado, tecidos com fistulas, neoplasias não removidas ou casos de osteomielite não tratada, da mesma forma, não merecem recomendação de tratamento. Justo porque, esses tipos de patologias, causariam um desenvolvimento precoce da própria doença. Além das contraindicações, podem acontecer algumas complicações.

Leitão F, et al. (2015), consideram complicações associadas ao uso da terapia: dor durante o uso devida pressão exercida, bem como agregada ao manejo e mudança do curativo ou cobertura de espuma. Descontinuidade no tecido no leito da ferida, levando a um atraso na cicatrização. Já Oliveira MC, et al. (2019); consideram também a dor como uma das complicações agregadas ao tratamento, porem pelo seu estudo realizado com 117 pacientes, além da dor, foi visto que os pacientes evoluíam com sangramento, por ocorrerem danos aos vasos sanguíneos adjacentes, e/ou hipertrofia dos tecidos de granulação. Isso acontece devido a hiper estimulação promovida pelo vácuo, gerando uma regeneração celular mais acentuada que o esperado, ocasionando um óbice no processo de cicatrização, com potencial suspensão da terapêutica, e após análise, escolha de um outro método de curativo ou oclusão. 
Oliveira MC, et al. (2019), defendem ainda que a TPN em aplicação por tempo prolongado é capaz de acarretar o desenvolvimento de transtornos psicológicos como ansiedade. Pode reduzir o bem-estar global do indivíduo ou ainda causar desnutrição. Nessas situações há de se pensar em um novo tipo de técnica, buscando evitar que o paciente evolua com mais uma tribulação.

A TPN também permite instilar soluções salinas, soluto de Dakin, betadine diluído ou outros agentes antissépticos, através do mesmo tubo que realiza o vácuo ou outra tubulação acessória, de maneira contínua ou descontínua (LEITÃO F, et al., 2015).

A terapia por pressão negativa convencional ainda é a mais utilizada em relação a Terapia por Pressão Negativa por Instilação (TPNi), que nada mais é que uma associação da TPN com a instilação de soluções fisiológicas ou antibioticoterapia, alguns estudos sugerem que quando comparadas, a última apresenta potencial de granulação superior, é também menos adesivo ao leito da ferida, gerando menos dor na retirada que a convencional, aumentando a espessura no processo de granulação em $2 \mathrm{~mm}$ quando confrontado com a TPN tradicional, acelerando o preparo do leito da ferida, permitindo o seu fechamento mais precoce (MILCHESKI DA, et al., 2017). Isso possibilita a hidratação da espuma com qualquer tipo de solução, sendo as mais utilizadas o soro fisiológico, tendo como finalidade umedecer a espuma e poder separar do tecido de granulação sem danos ao leito da ferida, ou ainda infundir antibióticos a fim de eliminar os micro-organismos existentes e acelerar a cicatrização.

\section{CONSIDERAÇÕES FINAIS}

Considerando todas as afirmações relatadas nesta revisão integrativa, nota-se a importância da utilização da Terapia por Pressão Negativa para o tratamento de feridas na prática clínica. A partir desta pesquisa pôdese perceber que os benefícios propiciados são, indubitavelmente, superiores às contraindicações e às complicações advindas da terapia, que age proporcionando uma regeneração mais rápida dos tecidos de granulação e consequentemente um processo cicatricial mais competente. Lamentavelmente ainda possui um investimento alto, se for utilizar o dispositivo V.A.C ${ }^{\circledR}$ sendo utilizado, na prática, por pacientes capazes de arcar de forma particular com essa despesa. Ainda é pouco explorado pelos profissionais de saúde, o sistema de vácuo dos próprios hospitais, o que diminuiria significativamente o custo, deixando de restrito aos mais abastados ou aos poucos planos de saúde que cobrem o tratamento. Por isso, uma terapêutica tão fantástica e com tantas vantagens e benefícios, deveria estar disponível para todos os pacientes acometidos por feridas complexas e não apenas as pessoas que podem pagar para utilizar esse tipo de tratamento.

\section{REFERÊNCIAS}

1. ABREU RLD, et al. Assistência de enfermagem no tratamento de feridas por terapia de pressão subatmosférica (VAC) na UTI. Revista Rede de Cuidados em Saúde, 2016; 10(2).

2. AZEVEDO AP, et al. Estudo da comparação de custos efetividade e tempo de tratamento de lesão por pressão em dois pacientes com o mesmo perfil clínico-patológico utilizando-se insumos e técnicas diferentes em cada um deles. Brazilian Journal of Health Review, 2020; 3(4): 10739-10755.

3. BENTO SS, et al. Associação do hidrogel e filme transparente no tratamento ferida crônica com necrose seca e úmida: Relato de experiência. Revista Enfermagem Atual In Derme, 2015; ed. 75.

4. BERTOLINI JP, et al. Protocolo de Assistência aos Usuários com Lesões de Pele. Videira (SC), Julho 2018; 65 p.

5. CALDAS NG, et al. O uso da terapia a vácuo no tratamento da Síndrome de Fournier - Revisão da literatura, experiência do serviço e serie de casos. Relatos de Casos Cirúrgicos, 2019; 3(42-46).

6. EBERHARDT TD, et al. Mensuração de feridas: revisão da literatura. Ciência e Saúde, Rio Grande do Sul, 2015; 8(2): 79-84.

7. GALLAFRIO ST, et al. Análise crítica do protocolo de tratamento da ferida operatória complicada após esternotomia para cirurgia cardíaca. Revista brasileira de cirurgia plástica, São Paulo, 2017; 32(2): 194-201.

8. GARGUR SM, SILVA GN. Protocolo de enfermagem na atenção primária. Protocolo de Feridas, Salvador, 2018.

9. KAMAMOTO F. Estudo comparativo entre o método USP de terapia por pressão negativa e o sistema V.A.C.® no tratamento de feridas traumáticas. São Paulo, 2016. Tese (doutorado) Faculdade de Medicina da Universidade de São Paulo. Programa de Ortopedia e Traumatologia. 
10. LEITÃO F, et al. Terapia por pressão negativa: uma opção no tratamento do pé diabético. Journal of Aging and Inovation, 2015; 4(1): 44-58.

11. LIMA RVKS, et al. Terapia por pressão negativa no tratamento de feridas complexas. Revista Coleção Brasileira Cirurgia., 2017; 44(1): 81-93.

12. MILCHESKI DA, et al. Experiência inicial com terapia por pressão negativa por instilação em feridas complexas. Revista do colégio brasileiro de cirurgiões, Rio de Janeiro, 2017; 44(4).

13. OLIVEIRA JFS, et al. Terapia por pressão negativa: benefícios no processo de cicatrização. Temas em Saúde, João Pessoa, 2017; 17(1): 52-65.

14. OLIVEIRA MC, et al. Terapia por pressão negativa no tratamento de infecção do sítio cirúrgico em cirurgia cardíaca. Revista Brasileira de Enfermagem, 2019; 73(5).

15. PEREIRA TO, et al. Terapia subatmosférica artesanal no tratamento de lesão por pressão. Brazilian Journal of Development, 2020; 6(1): 1560-1574.

16. PASSONI R, et al. Terapia por pressão negativa artesanal como adjuvante na autoenxertia cutânea em trauma ortopédico. Revista Enfermagem UFSM, 2015; 5(3): 580-588.

17. SANTOS TL, et al. Terapia por pressão negativa no tratamento de feridas. Revista eletrônica acervo saúde (REAS), 2019; 31: e1231.

18. SILVA ACO, et al. As principais coberturas utilizadas pelo enfermeiro. Revista Uningá, 2017; 53(2): 117-123, 2017.

19. SILVA JWL, et al. Manejo da terapia por pressão negativa (TPN) em lesões complexas. Brazilian Journal of Development, 2020; 6949-6958.

20. SOUSA LML, et al. A metodologia de revisão integrativa da literatura em enfermagem. Revista de Investigação em Enfermagem, 2017; 17-26. 